\section{Discussion}

The measures to be taken for tetanus prevention in an individual wounded patient are decided on the basis of a knowledge and understanding of the pathological process of tetanus, the mode of action and limitations of the various preventive measures available, and the nature of the patient's wound and his history of tetanus immunization. ${ }^{18}$ The recommendations should therefore be regarded not as a set of hard and fast rules but as guidelines since, as with any scheme of general guidance on medical practice, they will not invariably cover the circumstances of all individual patients.

In tetanus prevention it is of basic importance to establish and maintain active immunity. Tetanus immunization is recommended in the infant immunization schedules used in the United Kingdom and every effort should be made to ensure that all infants receive the proper course of injections, ${ }^{19}$ usually by means of combined vaccines. Unfortunately, many wounded patients will never have been immunized or do not know their history of immunization. Nevertheless, measures should be taken to ensure that such patients become actively immunized, and it is for this purpose that their recommended treatment at the time of injury includes an injection of toxoid, given as the first of a full course of injections. If this policy is adopted in time fewer and fewer patients should require human immunoglobulin for temporary protection at injury. The doctor should explain the significance of active immunization to his older patients so that increasing numbers of the population will come to realize the advantage of being immunized and of knowing their immunity status.

Wounded patients may require an antimicrobial for treatment or prevention of sepsis, and there is evidence that such treatment may sometimes usefully support the action of antitoxin in preventing tetanus. ${ }^{20} \mathrm{But}$, with the availability of human tetanus immunoglobulin, antimicrobials should now mainly revert to their former role of dealing with sepsis generally rather than the prevention of tetanus specifically; the use of antimicrobials was therefore not included in our recommendations.

\section{References}

1 Laurence, D. R., Evans, D. G., and Smith, J. W. G., British Medical fournal, 1966, 1, 33.

2 Lancet, 1974, 1, 51.

3 White, W. G., et al., fournal of Hygiene, 1973, 71, 283.

4 British Medical fournal, 1974, 1, 48.

${ }^{5}$ White, W. G., et al., Lancet, 1969, 2, 35.

${ }^{6}$ Peebles, T. C., et al., New England Fournal of Medicine, 1969, 280, 575.

7 Trinca, J. C., Infection and Immunity, 1974, 10, 1.

${ }^{8}$ Edsall, G., et al., fournal of the American Medical Association, 1967, 202 17.

9 Smith, J. W. G., and MacIver, A. G., Fournal of Medical Microbiology, $1974,7,497$.

10 Smith, J. W. G., British Medical Bulletin, 1969, 25, 177.

11 Glaser, J., and Wyss-Souffront, W. A., Pediatrics, 1961, 28, 367.

${ }^{12}$ Mackenzie, D. L., and Vlahcevic, Z. R., New England fournal of Medicine, 1974, 290, 749.

13 Trinca, J. C., Medical fournal of Australia, 1965, 2, 116.

14 Scheibel, I., et al., Acta Pathologica et Microbiologica Scandinavica, 1966, $67,380$.

15 Edsall, G., et al., in Proceedings of the Third International Conference on Tetanus, p. 102. Scientific Publication No. 253. Washington, Pan American Health Organisation, 1972.

16 MacLennan, R., et al., Bulletin of the World Health Organization, 1973, 49, 615.

${ }^{17}$ King, R. D., et al., Surgery, Gynecology, and Obstetrics, 1963, 116, 745.

${ }^{18}$ Adams, E. B., Laurence, D. R., and Smith, J. W. G., Tetanus. Blackwell, Oxford, 1969.

19 Department of Health and Social Security, Immunization Against Infectious Disease. London, H.M.S.O., 1972.

20 Smith, J. W. G., and MacIver, A. G., Fournal of Medical Microbiology, $1969,2,385$.

\title{
Fibrinogen Uptake Scanning for Diagnosis of Deep Vein Thrombosis: A Plea for Standardization
}

\author{
V. C. ROBERTS
}

British Medical fournal, 1975, 3, 455-458

\section{Summary}

From an examination of the factors affecting the diagnostic accuracy of the ${ }^{125} \mathrm{I}$-fibrinogen test for detecting deep vein thrombosis it is concluded that there is a greater possibility of error if postoperative counts are referred to the preoperative baseline rather than counts made immediately after operation. A method is proposed for reducing other errors caused by instrument mishandling.

\section{Introduction}

One of the most common hazards of modern surgery is the thrombosis that occurs postoperatively in the leg veins-deep

\footnotetext{
Department of Biomedical Engineering, King's College Hospital Medical School, London SE5 8RX

V. C. ROBERTS, PH.D., M.I.E.E., Lecturer
}

vein thrombosis (D.V.T.). In assessing the aetiology and techniques of prophylaxis clinical signs alone are an unreliable index and recently the radioisotopic ${ }^{125}$ I-fibrinogen test has been used. Several years' experience of this method has led to a general dissatisfaction with its precision in arriving at a positive diagnosis of thrombosis. This, together with the unjustifiability of denying an effective prophylactic to patients used as controls in clinical trials, prompted a reassessment of the use of ${ }^{125} \mathrm{I}$ scanning as a means of diagnosis.

Flancet al. ${ }^{1}$ first reported the use of ${ }^{125}$ I-fibrinogen; they used a scintillation counter and referred postoperative counts to preoperative baselines adjusting for both variations in background activity and physical (as opposed to biological) decay of the isotope. Their criterion for diagnosing thrombosis was a change in ratio of $>0.56$ between the highest and lowest counts on the same calf on any two occasions. They scanned the legs postoperatively and then on the third and sixth days. If counts rose during scanning the legs were scanned on subsequent daysthat is, days $1,2,4$, and 5 . Measurements were made at 2 -in $(5 \cdot 1-\mathrm{cm})$ intervals along the leg.

Shortly afterwards Negus et al. ${ }^{2}$ published what was to become the standard reference for diagnosis. They referred the radioisotope counts to the precordium and expressed them as a percentage of this count. The scans were also made every day 
after operation, but the readings were only made at 4-in (10.2$\mathrm{cm}$ ) intervals. The criterion for diagnosis of D.V.T. was "when a difference in the percentage uptake of 15 or more which persists and continues to rise is found between adjacent points on the same limb." No adjustment for variations in background readings were made. In the group of patients studied the correlation with phlebography of the positive isotope scans was $93 \%$ while the negative correlation was $100 \%$.

In 1970 Kakkar et al. ${ }^{3}$ published details of a modified technique of scanning using a new instrument, the Pitman 235 isotope monitor. This instrument was designed to overcome the large expenditure of time and effort in using conventional isotope counters for D.V.T. scanning. In a small portable instrument which could be manually set to read $100 \%$ over the precordium all subsequent readings were taken as direct percentage readings. There was, however, one small difference between the level of percentage difference taken to indicate D.V.T. According to Kakkar et al. comparison with their original work showed "that a rise of 20 or more in the percentage value would indicate a thrombus." Again no correction for daily variations in background radiation was proposed.

Other workers ${ }^{4-6}$ used Negus et al.'s criterion for diagnosis with sometimes minor but significant changes. Browse and Negus, ${ }^{6}$ for example, used "an absolute difference in count rate of more than $15 \%$ between adjacent points or the same points on the other leg which persisted or increased for more than 24 hours." Rosengarten and Laird ? suggested that "if the difference in percentage uptake between any two points on the legs, excluding that over the groin, exceeded 15 a diagnosis of deep vein thrombosis was made."

Another report which showed a $100 \%$ correlation with phlebography was that by Milne et al., ${ }^{8}$ who used the Pitman monitor and stated that the "criterion for a diagnosis of recent thrombus deposition was a sudden and sustained rise of $15 \%$ or more at any one point." This trial was one of the more reliable in that scans were made every day and not on selected days during the postoperative period, but Kakkar's level ${ }^{3}$ of $20 \%$ was ignored.

Sabri et al. ${ }^{10}$ tried to clarify the situation: if the "postoperative count of radioactivity at any site differed by at least $15 \%$ from (1) the preoperative value, (2) an adjacent site on the same leg, or (3) the same point on the other leg and persisted for more than 24 hours" then D.V.T. was diagnosed. A different criterion was advocated by Hills et al. ${ }^{11}$ Where researchers had been content to accept a raised count over 24 hours as diagnostic of thrombosis Hills et al.'s diagnosis was based on "a difference in percentage uptake of $15 \%$ or more between adjacent points on the same leg, or corresponding points on the opposite leg, if maintained for at least 48 hours."

By now, the move towards $20 \%$ as a diagnostic indicator was almost established. Gordon-Smith et al., ${ }^{12}$ for example, stated that the "criteria for diagnosis were as described by Negus et al., except that a persistant $20 \%$ difference between adjacent points or an equivalent point on the opposite leg was regarded as necessary for diagnosis." Bonnar and Walsh ${ }^{13}$ were more stringent and expanded the criterion to "an increase in counts of $20 \%$, compared with the count at the same point on the previous day, with the adjacent points on the same limb, and with the corresponding point on the opposite limb, was taken to indicate thrombosis on condition that the increase persisted and increased on the following days." The most important part of this statement is that in italics.

Even though this survey is incomplete, it should be clear that the criteria used for diagnosing thrombosis were too varied to permit any rational comparison between, for example, trials of different methods of prophylaxis. As prophylaxis becomes more effective the numbers of patients and hence the costs needed to reach significant levels increases. The need to be able to make some reasoned comparison between methods thus becomes more important.

Most workers who have had to analyse isotope scans will have met the occasional record which is difficult to diagnose. In a trial where two groups of patients are being compared in which the incidence is, for example, $30 \%$ in one group and $5 \%$ in the other one or two such records may not seriously affect the trial's outcome. But the same will not be true if the comparison is being made between groups of patients in which the incidence is $5 \%$ and $2 \%$; in this case the diagnosis must be unambiguous. An example of this ambiguity is the record of counts shown in table 1. The question that this record poses is: did this patient develop a small clot in the thigh on day 1 , clot almost the entire leg on day 2, and then undergo complete lysis by day 3 ? Intuitively one would argue that this could not have happened, but on some criteria this would be a positive diagnosis.

These are some of the problems which face anyone proposing to start a new clinical trial. What criteria should be used for diagnosis? Are there any major snags and, if so, how can they be overcome? This report is an attempt to establish some guidelines for the future.

TABLE I-Percentage Uptake Counts made on One Leg of Patient after Operation

\begin{tabular}{|c|c|c|c|c|}
\hline Position & After Operation & Day 1 & Day 2 & Day 3 \\
\hline $\begin{array}{l}1 \\
2 \\
3 \\
4 \\
5\end{array}$ & $\begin{array}{l}38 \\
30 \\
28 \\
28 \\
32\end{array}$ & $\begin{array}{c}\text { Groin } \\
80 \\
54 \\
28 \\
30 \\
22\end{array}$ & $\begin{array}{r}120 \\
110 \\
110 \\
100 \\
95\end{array}$ & $\begin{array}{l}38 \\
34 \\
32 \\
34 \\
36\end{array}$ \\
\hline $\begin{array}{r}6 \\
7 \\
8 \\
9 \\
10\end{array}$ & $\begin{array}{l}30 \\
30 \\
28 \\
26 \\
26\end{array}$ & $\begin{array}{c}\text { Knee } \\
28 \\
30 \\
30 \\
24 \\
32\end{array}$ & $\begin{array}{l}80 \\
70 \\
60 \\
52 \\
44\end{array}$ & $\begin{array}{l}38 \\
32 \\
31 \\
30 \\
32\end{array}$ \\
\hline 11 & 26 & $\underset{30}{\text { Ankle }}$ & 44 & 30 \\
\hline
\end{tabular}

\section{Factors Affecting Measurement}

Several factors may influence the readings made on the ${ }^{125} \mathrm{I}$-fibrinogen test: (a) The magnitude of the dose of ${ }^{125} \mathrm{I}$ will affect the absolute count but should not affect the precordial-referred percentage readings. If the dose is lower than believed, however, the proportion of the count contributed by background radiation becomes more important, particularly during the later postoperative period. (b) In the precordium-referred scan slight misplacement of the probe in establishing the precordial count will lead to the wrong value being used. This will effectively scale all subsequent percentage readings either up or down by some unknown but, nevertheless, constant factor. (c) The blood volumes and the relative blood flow rates in the regions being monitored will affect the readings. Variations may occur-for example, with peripheral vasodilation or vasoconstriction.

\section{HAEMODYNAMIC EFFECTS}

To assess the last of these possible sources of error the records of patients who had undergone fibrinogen scanning for at least seven days were analysed. This group of patients all had ${ }^{125} \mathrm{I}$ administered preoperatively. Each was monitored with a Pitman ratemeter before and immediately after operation and on each of the six following days. Readings were referred to the precordium by placing the probe over the fourth intercostal space to the left of the sternum and setting the machine.to read $100 \%$. Readings on the legs were made at $5 \cdot 1-\mathrm{cm}$ intervals from ankle to thigh. To eliminate venous pooling in the calf veins the legs were raised $30^{\circ}$ before measurements. Background radiation was also measured by pointing the probe away from the patient.

In the analysis of the scans any record in which the background exceeded $10 \%$ of the precordial count was excluded, as was any record which showed a rise, transient or sustained, which was in any way suggestive of an underlying thrombosis. This left 30 patients' scan records, which were then analysed to find the mean value at each point on each day, the records for both legs being integrated. Thus, the value of the percentage reading at each point was the mean value of 60 readings and the analysis was based on a total of 5865 readings. In table II the mean values of the percentage reading and the background percentage are shown. 
TABLE II-Mean Percentage Counts Taken from 30 Patients over Seven Days. Readings were Integrated for Both Legs. Rounded Standard Deviations are Given in Parentheses

\begin{tabular}{|c|c|c|c|c|c|c|c|c|}
\hline Position & Before Operation & After Operation & Day 1 & Day 2 & Day 3 & Day 4 & Day 5 & Day 6 \\
\hline $\begin{array}{r}1 \\
2 \\
3 \\
4 \\
5 \\
6 \\
7 \\
8 \\
9 \\
10 \\
11\end{array}$ & $\begin{array}{l}24(9) \\
22(7) \\
21(7) \\
20(6) \\
19(6) \\
25(9) \\
27(10) \\
27(11) \\
26(11) \\
24(9) \\
21(7)\end{array}$ & $\begin{array}{l}27(6) \\
26(7) \\
25(7) \\
26(8) \\
26(8) \\
27(8) \\
29(9) \\
29(9) \\
29(9) \\
27(8) \\
25(7)\end{array}$ & $\begin{array}{l}29(9) \\
27(8) \\
25(8) \\
26(8) \\
26(8) \\
28(9) \\
29(10) \\
29(10) \\
29(10) \\
27(10) \\
25(9)\end{array}$ & $\begin{array}{l}29(9) \\
27(8) \\
26(8) \\
26(7) \\
25(7) \\
27(9) \\
28(10) \\
28(10) \\
27(10) \\
26(10) \\
24(9)\end{array}$ & $\begin{array}{l}32(8) \\
28(8) \\
28(9) \\
26(8) \\
26(8) \\
27(9) \\
29(9) \\
28(10) \\
28(10) \\
26(9) \\
25(8)\end{array}$ & $\begin{array}{l}32(10) \\
29(8) \\
27(7) \\
27(7) \\
27(7) \\
27(7) \\
27(7) \\
28(8) \\
26(7) \\
25(8) \\
23(7)\end{array}$ & $\begin{array}{l}33(10) \\
30(9) \\
29(8) \\
29(7) \\
28(8) \\
29(7) \\
28(7) \\
28(6) \\
27(6) \\
25(5) \\
24(5)\end{array}$ & $\begin{array}{l}32(9) \\
30(8) \\
29(7) \\
29(7) \\
30(6) \\
30(7) \\
31(7) \\
31(7) \\
30(7) \\
29(7) \\
27(6)\end{array}$ \\
\hline Background & $2(1)$ & $2(1)$ & $3(2)$ & $3(2)$ & $5(2)$ & $5(2)$ & $5(2)$ & $5(2)$ \\
\hline
\end{tabular}

TABLE III-Positions at which Significant Changes in Readings $(P<0.01)$ Occurred when Referred to Preoperative Readings. Results when Changes in Background Counts were Ignored are Compared with Those when Such Counts were Taken into Account

\begin{tabular}{|c|c|c|c|c|c|c|c|c|c|c|c|c|c|c|}
\hline \multirow{2}{*}{ Position } & \multicolumn{7}{|c|}{ Neglecting Background } & \multicolumn{7}{|c|}{ Taking Account of Background } \\
\hline & After Operation & Day 1 & Day 2 & Day 3 & Day 4 & Day 5 & Day 6 & After Operation & Day 1 & Day 2 & Day 3 & Day 4 & Day 5 & Day 6 \\
\hline $\begin{array}{r}1 \\
2 \\
3 \\
4 \\
5 \\
6 \\
7 \\
8 \\
9 \\
10 \\
11\end{array}$ & $\begin{array}{l}+ \\
+ \\
+\end{array}$ & $\begin{array}{l}+ \\
+ \\
+ \\
+\end{array}$ & $\begin{array}{l}+ \\
+ \\
+ \\
+ \\
+\end{array}$ & $\begin{array}{l}+ \\
+ \\
+ \\
+ \\
+\end{array}$ & $\begin{array}{l}+ \\
+ \\
+ \\
+ \\
+\end{array}$ & $\begin{array}{l}+ \\
+ \\
+ \\
+ \\
+\end{array}$ & $\begin{array}{l}+ \\
+ \\
+ \\
+ \\
+ \\
+ \\
\\
+ \\
+\end{array}$ & $\begin{array}{l}+ \\
+ \\
+\end{array}$ & $\stackrel{+}{+}$ & $\stackrel{+}{+}$ & $\begin{array}{l}+ \\
+ \\
+ \\
+ \\
+\end{array}$ & $\begin{array}{l}+ \\
+ \\
+ \\
+ \\
+\end{array}$ & $\begin{array}{l}+ \\
+ \\
+ \\
+ \\
+\end{array}$ & $\begin{array}{l}+ \\
+ \\
+ \\
+\end{array}$ \\
\hline
\end{tabular}

TABLE IV-Positions at which Significant Changes in Readings Occurred when Referred to Postoperative Readings and Taking into Account Background Counts

\begin{tabular}{|c|c|c|c|c|c|c|}
\hline \multirow{2}{*}{ Position } & \multicolumn{6}{|c|}{ Day after Operation } \\
\hline & 1 & 2 & 3 & 4 & 5 & 6 \\
\hline $\begin{array}{r}1 \\
2 \\
3 \\
4 \\
5 \\
6 \\
7 \\
8 \\
9 \\
10 \\
11\end{array}$ & & & & $\begin{array}{l}+ \\
+ \\
+\end{array}$ & $\begin{array}{l}+ \\
+ \\
+ \\
+\end{array}$ & \\
\hline
\end{tabular}

The next stage in the assessment was to discover whether the postoperative percentage counts differed significantly from any given baseline. The result was considered significant if the $P$ value on Student's $t$ test was $<0.01$. Table III shows the positions where significant changes with respect to the preoperative counts were observed. When the background count was neglected there were 35 significant changes out of a possible 77 -that is, almost $50 \%$. When the background radiation was taken into account $t_{5}$ subtracting it from the measured percentage at any point the number of significant changes fell to 26 .

When the initial postoperative scan was taken as the baseline, and the correction for background radiation applied the number of points where there were significant changes fell even further (table IV). There were only eight positions out of 66 where significant changes were found. This was just over a quarter of the total found when the readings were referred to the preoperative scan and background variations ignored.

\section{INSTRUMENT MISHANDLING}

The instrument itself may be wrongly set. If the probe is placed over the precordium in slightly different positions on different occasions, or even tilted slightly in relation to the skin, the effective source of radiation will change. Such positional variations may occur, for example, when the instrument operator is adjusting the scale of the isotope monitor to $100 \%$. Other radiation source variations can arise from movements of the vasculature within the chest cavity, as may happen with the patient moving from the fully recumbent to the semi-recumbent position.

Clearly, any variations in the position of this reference source will affect the relative magnitude of the leg counts. Some method of correcting for this possibility should therefore be applied before counts are analysed.

Examination of table II shows that the scan positions where the smallest variations in counts occur are the positions above the knee. Furthermore, venous thrombi are least likely to occur in these positions. This suggests that the readings (from, for example, positions 2-5) could be used as a scaling factor to correct for probe misplacement; this could be done by summing these four readings on each day, taking a ratio with respect to, for example, the preoperative baseline, and multiplying all readings by this scaling factor. If we take the figures from table II the sum of the preoperative counts in positions 2-5 after correcting for the background is 74. The similar count on the postoperative counts come to 95 . Thus all the readings on the postoperative counts should be scaled down by $74 / 95$ or $0 \cdot 78$. Thus, the variation in counts in relation to the preoperative level is effectively halved.

\section{Discussion}

Clearly, significant changes in percentage counts do occur on most days after operation (with respect to the preoperative counts), particularly in the thigh. If the postoperative counts are referred to preoperative counts for diagnosis without correcting for background then false-positive diagnoses may be made in the thigh - that is, there are significant increases in the counts in the thigh which artificially lower the degree of thrombus formation needed before a positive diagnostic level is achieved. If, however, postoperative counts are referred to the immediate postoperative scan and corrected for variations in background false-negative diagnoses may be made in the calf region-that is, there are significant decreases in the counts in the calf region which artificially raise the degree of thrombus formation needed before a positive diagnostic level is reached).

The number of potential false-positive sites among 30 patients whose scans were analysed was 35 . The number of potential false-negative sites was eight. All monitored positions showed variations in percentage count, the largest occurring consistently in the calf (maximum S.D. 11) and the smallest (maximum 
S.D. 9) above the knee. The size of the largest natural variations suggests that the difference of $20 \%$ as a diagnostic determinant is better than the level of $15 \%$.

In general, these findings suggest that the ${ }^{125} \mathrm{I}$-fibrinogen test, even without supporting evidence of phlebography, can lead to false diagnoses of D.V.T. As techniques of prophylaxis become more successful it becomes more important that diagnosis is totally unambiguous. Furthermore, it becomes progressively more important for trial results to be compared. Hence, clinical trials should take some account of the value of a standard method of both monitoring and subsequent analysis, possibly incorporating the following principles: the precordial reading should always be made with the subject fully recumbent; all readings should be corrected for daily variations

TABle v-Diagnostic Percentage Uptake Counts for Patient in Table I after Correction for Background and Probe Mishandling

\begin{tabular}{c|c|c|c|c}
\hline Position & After Operation & Day 1 & Day 2 & Day 3 \\
\cline { 1 - 3 } & 36 & 58 & 21 & 23 \\
2 & 28 & 38 & 21 & 22 \\
3 & 26 & 18 & 21 & 23 \\
4 & 26 & 20 & 21 & 25 \\
5 & 30 & 26 & 21 & 26 \\
6 & 28 & 18 & 28 & 22 \\
7 & 28 & 20 & 28 & 21 \\
8 & 26 & 20 & 23 & 22 \\
9 & 24 & 15 & 24 & 22 \\
10 & 24 & 21 & 23 & 20 \\
11 & 24 & 20 & & \\
\hline
\end{tabular}

in the background; patients should be monitored every day for not less than six days and readings should be made at 2 -in $(5 \cdot 1-\mathrm{cm})$ intervals; the readings should be corrected for the possibilities of instrument mishandling; in reaching a diagnosis readings at each position on the leg should be compared (after correction for background and probe placement) with the immediate postoperative scan. A difference of $20 \%$ or more at any position on two or more consecutive days should be taken to indicate a thrombosis.

To indicate the effectiveness of this technique the readings for the patient in table I were corrected according to these guidelines. It was discovered that the readings on day 2 had been taken only minutes after the patient had returned to the ward after radiotherapy. The corrected readings are shown in table V. It was taken (perhaps incorrectly) that this patient, though developing a small clot in position 1 on day 1 , did nol clot her entire leg on day 2 . Unfortunately phlebography was not performed.

I am indebted to Mrs. D. Berlyn for help with the statistical analysis. The work was financed through the generosity of the Wates Foundation and the British Heart Foundation.

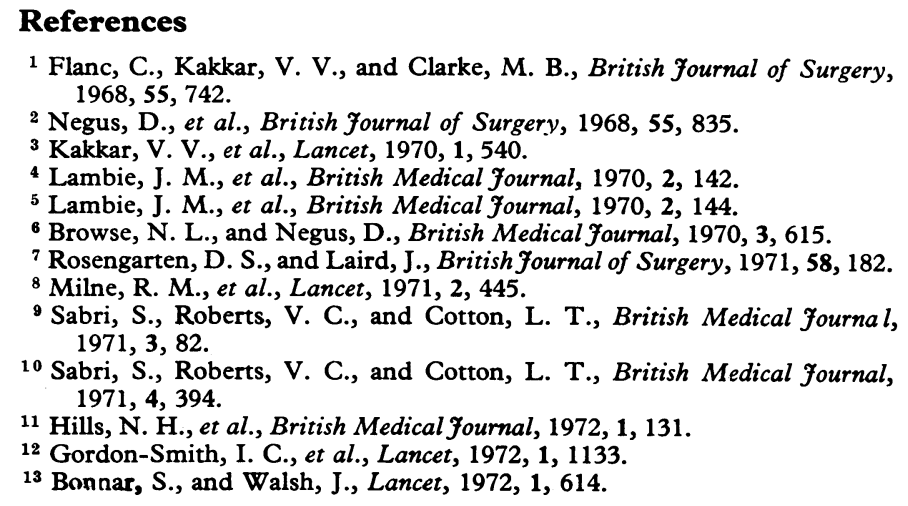

\section{References}

Flanc, C., Kakkar, V. V., and Clarke, M. B., British fournal of Surgery,

3 Kakkar, V. V., et al, Lancet, 1970, 1, 540.

4 Lambie, J. M. et al., British Medical fournal, 1970, $2,142$.

${ }^{5}$ Lambie, J. M., et al., British Medical fournal, 1970, 2, 144.

Milne, R. M et al., Lancet, 1971, 2, 445 .

Sabri, S., Roberts, V. C., and Cotton, L. T., British Medical fournal, $1971,3,82$

1971, 4, 394.

2 Gordon-Smith, I. C., et al., Lancet, 1972, 1, 1133.

13 Bonnar, S., and Walsh, J., Lancet, 1972, 1, 614.

\title{
Failure of Low-dose Heparin to Improve Efficacy of Peroperative Intermittent Calf Compression in Preventing Postoperative Deep Vein Thrombosis
}

\author{
V. C. ROBERTS, L. T. COTTON
}

British Medical fournal, 1975, 3, 458-460

\section{Summary}

The possible benefits of adding a low-dose heparin regimen to the technique of peroperative intermittent calf compression for preventing deep vein thrombosis (D.V.T.) were assessed in a randomized trial in 84 surgical patients. The efficacy of peroperative intermittent calf compression was not enhanced by a low-dose heparin regimen, but neither was it worsened. Age, weight, duration, operation, and malignant disease did not affect the relative effectiveness of the two regimens of prophylaxis. The results confirmed that venous stasis is the principal cause of D.V.T.

\footnotetext{
Department of Biomedical Engineering, King's College Hospital Medical School, London SE5 8RX

V. C. ROBERTS, PH.D., M.I.E.E., Lecturer

L. T. COTTON, M.CH., F.R.C.S., Consultant Surgeon and Director of Department
}

\section{Introduction}

Over the past five years considerable advances have been made in the search for an effective method of preventing postoperative deep vein thrombosis (D.V.T.) and its sequelae. Latterly, successful methods have fallen into two classes-those using low-dose subcutaneous heparin designed to prevent thrombus formation, and those using physical techniques designed to prevent venous stasis. It has long been argued that the principal causes of venous thrombosis are $(a)$ a change in the biochemistry of the blood, (b) physical damage to the lining of the vessel wall, and $(c)$ stasis of blood within the veins. Little can effectively be done to measure or control $b$, which perhaps explains the concentrated effort that has been expended on the remaining two.

In the belief that venous stasis is the principal initiating factor of venous thrombosis we have concentrated our efforts on physical methods of stimulating the venous flow. We have been able to show the efficacy of a very simple method of prophylaxis using intermittent calf compression during operation. This technique, which was derived from extensive haemodynamic investigations, ${ }^{12}$ reduces the incidence of postoperative thrombosis by up to $90 \% .^{3}{ }^{4}$ Despite its apparent success and evident simplicity, however, we have been unable to prevent totally postoperative thrombosis with this method. One possible reason 